\title{
Selecting the Optimal Micro-Grid Planning Program Using a Novel Multi-Criteria Decision Making Model Based on Grey Cumulative Prospect Theory
}

\author{
Haoran Zhao ${ }^{1,2}$, Sen Guo ${ }^{1,2, *}$ and Huiru Zhao ${ }^{1,2}$ \\ 1 School of Economics and Management, North China Electric Power University, Beijing 102206, China; \\ haoranzhao0118@163.com (H.Z.); zhaohuiru@ncepu.edu.cn (H.Z.) \\ 2 Beijing Key Laboratory of New Energy and Low-Carbon Development, North China Electric Power \\ University, Changping, Beijing 102206, China \\ * Correspondence: guosen324@163.com; Tel.: +86-158-1142-4568
}

Received: 23 May 2018; Accepted: 10 July 2018; Published: 13 July 2018

\begin{abstract}
As useful supplements and effective support for large-scale electric power networks, micro-grid systems are the development tendency of future electric power systems. The planning performance of a micro-grid not only affects its security, reliability and economy, but also has a profound influence on the stable operation of large-scale electric power networks with the increasing penetration of micro-grids. Hence, studies related to micro-grid planning program evaluation are of great significance. This paper established a novel multi-criteria decision making (MCDM) model combining the best-worst method (BWM), the entropy weighting approach, and grey cumulative prospect theory for optimum selection of micro-grid planning programs. Firstly, an evaluation index system containing 18 sub-criteria was built from the perspectives of economy, electricity supply reliability and environmental protection. Secondly, the weights of sub-criteria were calculated integrating the subjective weights judged by the BWM and the objective weights computed by the entropy weighting method. Then, the cumulative prospect theory (CPT) combined with grey theory was employed to select the optimal micro-grid planning program. The empirical result indicates that the program with $100 \mathrm{kWp}$ photovoltaic power generation unit, $200 \mathrm{~kW}$ wind power generation unit and $600 \mathrm{kWh} \mathrm{NaS}$ battery energy storage system is the optimal micro-grid planning program. To verify the robustness of obtained result, a sensitivity analysis related to values change of parameters under different risk preferences was conducted, and the result indicates that the selected optimal micro-grid planning program will not be influenced by various risk preferences of decision makers (DMs) and investors. The novel MCDM proposed in this paper is applicable and feasible in the micro-grid planning programs evaluation and selection.
\end{abstract}

Keywords: micro-grid planning evaluation; best-worst method; grey cumulative prospect theory; risk preferences

\section{Introduction}

With the growth of national economies, the demand for electricity has increased sharply, which brings about the expansion of the electricity grid scale. The resulting ultra-large-scale electricity systems are becoming increasingly complicated and difficult to operate, so it is difficult to meet the increasing demand for safe and reliable electricity supply. In particular, large-scale electricity outages often occur throughout the world (such as the interruption of electricity supply for more than 15 million European households that happened in 2006) [1], which can lead to inestimable losses to the whole social and economic development environment and completely expose the vulnerability of large-scale electricity grids. Additionally, thermal power generation plants, which consume large amounts of fossil 
fuels and generate massive atmospheric pollutants, are dominant in China [2]. With the continuous improvement of environmental protection requirements, it is urgent to develop green energy-based electricity generation patterns $[3,4]$ and promote the sustainable development of the energy industry. Distributed power generation can utilize the renewable energy existing in decentralized forms, reduce the transmission and distribution distance, and improve the reliability and sustainability of electric power systems [5]. However, the grid connection of different distributed electricity generation types will bring adverse influences on electricity quality, system protection and operation which will cause great impacts on the electricity grid and electricity users. The concept of micro-grids is gradually proposed to guarantee the reliable connection and effective use of the distributed generation as well as maximize the advantages of distributed generation technologies in the fields of economy, energy, and environment [6]. A micro-grid is an independent electricity supply system integrating electricity generation and electricity consumers, which is composed of distributed electricity generation units, energy storage systems, electronic devices, monitoring systems, and electricity loads. Currently, many countries incorporate micro-grids into their future electricity grids $[7,8]$.

Recently, China's central government has emphasized the importance of the planning and operation of micro-grid demonstration projects [9]. In July 2017, at the aim of promoting the structural reform of energy supply side as well as prompting and standardizing the healthy and sustainable development of the micro-grid, the National Development and Reform Commission and the State Energy Bureau have formulated 'Pilot Measures for Promoting the Construction of the Grid Connected Micro-grid' [10] and issued the 'Notice on the List of New Energy Micro-grid Demonstration Projects' [11]. A total of 28 renewable energy micro-grid demonstration projects are approved, among which 24 demonstration projects are grid connected micro-grids and four demonstration projects are independent micro-grids. With the maturity of micro-grid technologies and the increase of micro-grid demonstration projects, the development of micro-grids is gradually heading for large-scale development mode. The planning and design of micro-grids is a significant part of the early stage of micro-grid construction aiming at determining the type, capacity, and position of distributed generation units and energy storage systems as well as grid structure. To identify the optimum micro-grid planning program, it is necessary to evaluate the existing micro-grid planning programs considering economy, electricity supply reliability, and environmental protection perspectives. Therefore, it is necessary to establish the evaluation index system and evaluation model for different micro-grid planning programs, which aim to select the optimal micro-grid system.

According to the existing literature related to micro-grid planning, it can be discovered that most of them employ net present value (NPV) maximization or investment cost minimization of micro-grid to be the objective function to build optimization models in order to obtain the optimum solutions [12-20]. Shu et al. [21] established a planning model for the islanded micro-grid taking the comprehensive cost minimization as objective function solved by genetic algorithm. Han et al. [22] proposed a planning model for grid-connected micro-grid systems with photovoltaic and energy storage systems based on cost-benefit analysis, which considers photovoltaic subsidy policy, time-of-use electricity price, and two-part tariffs. Several optimization algorithms and interior-point algorithm were utilized to solve the established model, and the results showed that the economic benefit calculated by the particle swarm optimization method is higher than those of other methods. Nieto et al. [23] analyzed the influences of distributed generation (DG) units on electricity grid systems and integrated them with energy storage systems with various capacities to improve the electricity quality. Results showed that the integration of energy storage systems can greatly improve the electricity supply reliability, and hence the planning of distribution generation system is of great significance. Vita [24] proposed a decision-making model for the optimal location selection and size of DG units to be incorporated into distribution networks, which can help distribution system operators and engineers master the integration of DG units into current distribution systems. Chen et al. [25] employed the analytic hierarchy process (AHP) and Delphi approach to analyze the assessment indicators of islanded micro-grid systems and evaluated the micro-grid systems under the control strategies of cycle charge, 
wind-solar-diesel, and wind-solar-energy storage. Vasiljevska et al. [26] discussed the influences of different electricity price mechanisms, energy price, micro-grid operation modes, and load supply and demand differences on large scale integration of micro-grids, and evaluated several micro-grids from the perspectives of micro-grid control, construction and operation. Miao et al. [27] utilized four indices, which are average system availability indicator, max short-circuit current, annual expense per load unit and max voltage drop, to comprehensively evaluate the connection modes of distribution network to find the most suitable connection mode for micro-grid users. The results illustrate that the radial connection mode is the most appropriate one for micro-grid users considering economic efficiency. Yang et al. [28] evaluated the micro-grids at the planning stage from reliability, market orientation, economic, and environmental perspectives based on AHP methodology. Most of the existing literature about micro-grid planning focus on generation unit capacity optimization and energy storage technology. However, before micro-grid construction, it is of great significance to perform a scientific evaluation of various planning optimization programs to guarantee the economic efficiency and operational reliability of the established micro-grid systems. Therefore, this paper focuses on establishing a comprehensive evaluation model based on multi-criteria decision making (MCDM) theory to comprehensively and scientifically evaluate the potential micro-grid planning programs from economy, electricity supply reliability, and environmental protection perspectives and finally select the optimal planning program for micro-grid construction.

The primary contribution of this paper is to establish a novel MCDM model combining the BWM, entropy weighting approach and grey cumulative prospect theory (GCPT) for optimum planning program selection of micro-grid construction. Firstly, considering that the micro-grid aims at achieving safety, reliable, high efficient, economic, and sustainable operation goal, a comprehensive evaluation index system is established in terms of economy, electricity supply reliability, and environmental protection. As economic criterion, it contains seven sub-criteria to reflect the cost and profitability of micro-grid systems. For the electricity supply reliability criterion, it embodies eight sub-criteria to reflect the reliability of electricity supply and micro-grid systems operation. For the environmental protection criterion, it includes three sub-criteria to reflect the utilization of renewable energy and the reduction of pollutants. Secondly, the weights of sub-criteria are computed by the integration of entropy weighting approach and the best-worst method (BWM) which is a pair-wise comparison method and more convenient and consistent than AHP. Thirdly, the comprehensive assessment model is established on the basis of GCPT to select the optimum planning program. The cumulative prospect theory (CPT) can reflect the behaviors of investors and decision makers (DMs) when they are confronting risks. Since CPT has clear logic as well as a relatively simple computation procedure, it has been extensively applied in various assessment and decision-making problems [29-34]. Considering that grey theory can handle uncertainties in decision-making problems [35,36], this paper extends the CPT via introducing grey theory for micro-grid planning programs selection. Finally, the established novel MCDM model is applied to select the optimal micro-grid planning program from three different programs.

The remainder of this paper is structured as follows: Section 2 introduces the basic theory utilized to establish the novel MCDM model. Section 3 constructs the framework of selecting the optimum micro-grid planning program using the novel MCDM model. Section 4 establishes the comprehensive evaluation index system. The evaluation procedure will be empirically conducted in Section 5 . Section 6 discusses the empirical results and elaborates the sensitivity analysis. Section 7 will draw the main conclusions.

\section{Basic Methodologies for the Established Novel MCDM Model}

To evaluate the micro-grid planning programs and select the optimal one for micro-grid construction, considering the characteristics of micro-grids, the evaluation index system from the perspectives of economy, electricity supply reliability, and environmental protection is firstly established. To comprehensively reflect the significant degree of each sub-criterion, the weights are determined by combining the subjective weights taking experts opinions into account and objective 
weights taking actual data into account. The subjective weights are identified by the BWM method, which is a pair-comparison method and more coherent than AHP. The objective weights are calculated by the entropy weighting method which can retain all information of actual criteria data. Considering that the construction of micro-grids may confront with various risks and the strategy makers and investors of micro-grid systems may have different risk preferences, the CPT combined with grey theory is applied to evaluate the micro-grid planning programs which can reflect different risk preferences and handle uncertainties in decision making. Thus the basic methodologies for the established MCDM model contain the BWM, entropy weighting approach, and GCPT in this paper.

\subsection{The $B W M$}

BWM, as an innovative pairwise comparison based method, only requires $2 n-3$ ( $n$ is the amount of sub-criteria in the index system) comparisons [37-39], which is much more convenient and coherent than AHP [40-42]. Considering about the simplicity and the superiority of the BWM, it is extensively employed in many research fields [43-47]. The procedures of the BWM are introduced as below:

Step 1: In terms of the characteristics of the evaluated alternatives, the index system $\left\{I_{1}, I_{2}, \ldots, I_{n}\right\}$ is constructed.

Step 2: Choose the best and the worst sub-criteria from the index system in accordance with experts' preferences. The determination of them only takes the important degree of each sub-criterion into consideration.

Step 3: Evaluate the important degree between the best sub-criterion and others represented by the number from 1 to 9 . The greater the value is, the more critical the best sub-criterion over others. The comparing results are expressed as:

$$
A_{B}=\left(a_{B 1}, a_{B 2}, \ldots, a_{B n}\right)
$$

where $a_{B i}$ indicates the critical degree of the best sub-criterion over sub-criterion $i$, and $a_{B B}=1$.

Step 4: Evaluate the critical degree between others and the worst sub-criterion represented by the number from 1 to 9 . The comparing results are expressed as:

$$
A_{W}=\left(a_{1 W}, a_{2 W}, \ldots, a_{n W}\right)^{T}
$$

where $a_{i W}$ implies the critical degree of sub-criterion $i$ over the worst one, and $a_{W W}=1$.

Step 5: Obtain the weights $\left(w_{1}^{*}, w_{2}^{*}, \ldots, w_{n}^{*}\right)$. Aiming at obtaining the optimal weights, the maximum absolute differences $\left\{\left|w_{B}-a_{B i} w_{i}\right|,\left|w_{i}-a_{i W} w_{W}\right|\right\}$ of all sub-criteria need to be minimized written as:

$$
\begin{gathered}
\min \max _{i}\left\{\left|w_{B}-a_{B i} w_{i}\right|,\left|w_{i}-a_{i W} w_{W}\right|\right\} \\
\text { s.t. } \\
\sum_{i} w_{i}=1 \\
w_{i} \geq 0, \text { for all } i .
\end{gathered}
$$

To simplify the computational process, Equation (3) is transformed into linear form as:

$$
\begin{aligned}
& \min \xi \\
& \text { s.t. } \\
& \left|w_{B}-a_{B i} w_{i}\right| \leq \xi \text {, for all } i \\
& \left|w_{i}-a_{i W} w_{W}\right| \leq \xi \text {, for all } i \\
& \sum_{i} w_{i}=1 \\
& w_{i} \geq 0 \text {, for all } i \text {. }
\end{aligned}
$$

By computing Equation (4), the unique and optimal weights are obtained. 
Step 6: Examine the comparison coherence. By computing Equation (4), the results of $\xi$ can also be obtained which will be applied to coherence examination. The coherence index is identified by the comparing value of $a_{B W}$ illustrated in Table 1 . The coherent ratio (CR) is calculated as:

$$
\text { Coherent ratio }=\frac{\xi^{*}}{\text { Coherent indicator }}
$$

The smaller the $\xi^{*}$ is, the more consistent the comparison is.

Table 1. Coherent Indicator (CI).

\begin{tabular}{cccccccccc}
\hline $\boldsymbol{a}_{\boldsymbol{B W}}$ & $\mathbf{1}$ & $\mathbf{2}$ & $\mathbf{3}$ & $\mathbf{4}$ & $\mathbf{5}$ & $\mathbf{6}$ & $\mathbf{7}$ & $\mathbf{8}$ & $\mathbf{9}$ \\
\hline $\mathrm{CI}\left(\max \xi^{*}\right)$ & 0.00 & 0.44 & 1.00 & 1.63 & 2.30 & 3.00 & 3.73 & 4.47 & 5.23 \\
\hline
\end{tabular}

\subsection{The Entropy Weighting Method}

Generally, the entropy weighting approach has been utilized to calculate the weights of quantitative sub-criteria which can collect actual data $[48,49]$. The elaborated procedure of this method is presented as follows:

Step 1: Normalize the initial evaluated performance values of sub-criteria. The initial evaluated performance value is normalized as:

$$
p_{i j}=\frac{x_{i j}}{\sum_{j=1}^{m} x_{i j}}
$$

where $x_{i j}$ and $p_{i j}$ imply the initial evaluated performance value and the normalized value of the $i$ th sub-criterion for evaluated object $j$, and $m$ is the amount of evaluated objects.

Step 2: Calculate the entropy values. $e_{i}$ is the entropy value represented by:

$$
e_{i}=-k \sum_{j=1}^{m} p_{i j} \ln \left(p_{i j}\right)=-\frac{1}{\ln m} \sum_{j=1}^{m} p_{i j} \ln \left(p_{i j}\right)
$$

Step 3: Compute the deviation degree $g_{i}$ of the $i$-th sub-criterion as:

$$
g_{i}=1-e_{i}
$$

Step 4: Obtain the weights of quantitative sub-criteria. The weights $\lambda_{i}$ of quantitative sub-criterion $i$ are computed as:

$$
\lambda_{i}=\frac{g_{i}}{\sum_{i=1}^{n} g_{i}}
$$

\subsection{Grey Cumulative Prospect Theory}

The CPT, established by Kahneman and Tversky [50,51], is a useful methodology for assessment and decision making confronting with risk and uncertainties. The prospect value $V$ in CPT is calculated by the value function $v(x)$ and the weight function $\pi(w)$ written as:

$$
V_{j}=\sum_{i=1}^{n} \pi\left(w_{i}\right) v\left(x_{i j}\right)
$$

$v(x)$ represents risks preference, and $\pi(w)$ indicates the decision weights. Both of them are calculated as:

$$
v\left(x_{i j}\right)= \begin{cases}x_{i j}^{\alpha} & x_{i j} \geq 0 \\ -\lambda\left(-x_{i j}\right)^{\beta} & x_{i j}<0\end{cases}
$$




$$
\pi\left(w_{i}\right)= \begin{cases}\frac{w_{i}^{\eta}}{\left(w_{i}^{\eta}+\left(1-w_{i}\right)^{\eta}\right)^{1 / \eta}} & x_{i j} \geq 0 \\ \frac{w_{i}^{\delta}}{\left(w_{i}^{\delta}+\left(1-w_{i}\right)^{\delta}\right)^{1 / \delta}} & x_{i j}<0\end{cases}
$$

where $x_{i j}$ indicates the gains $\left(x_{i j} \geq 0\right)$ and losses $\left(x_{i j}<0\right), \alpha$ and $\beta$ are concavity and convexity parameters, $\alpha=\beta=0.88$ [50], $\lambda$ demonstrates the risk aversion coefficient, $\lambda=2.25, \eta$ and $\delta$ represent the attitude towards gains and losses, $\eta=0.61$, and $\delta=0.69$ [50].

Through combining the grey theory, the value function is reformulated as:

$$
v\left(x_{i j}\right)= \begin{cases}\left(1-\xi_{i j}\right)^{\alpha} & x_{i j} \geq r \\ -\lambda\left[-\left(\xi_{i j}-1\right)\right]^{\beta} & x_{i j}<r\end{cases}
$$

where $r$ is supposed to be the reference solution, $\xi_{i j}$ represents the grey correlation degree between $x_{i j}$ and $r$, which can be calculated as:

$$
\xi_{i j}=\frac{\min _{i} \min _{j}\left|x_{i j}-r\right|+\rho \max _{i} \max _{j}\left|x_{i j}-r\right|}{\left|x_{i j}-r\right|+\rho \max _{i} \max _{j}\left|x_{i j}-r\right|}
$$

where $\rho$ is the identification coefficient in the interval of $[0,1]$.

\section{The Procedure of the Established MCDM Model for Selecting the Optimal Micro-Grid Planning Program}

The established MCDM method for prioritizing different micro-grid planning programs systematically integrates the BWM, entropy weighting method, and GCPT. The procedure of the established MCDM model is illustrated as follows:

Step 1: Construct the evaluation index system for the optimal micro-grid planning program selection. The evaluation index system should be constructed prior to the performance evaluation of different micro-grid planning programs considering the characteristics of micro-grids.

Step 2: Assign the performance values for the qualitative sub-criteria of each micro-grid planning program. Considering that qualitative sub-criteria may exist in the constructed evaluation index system which cannot collect actual data, the BWM is employed to assign performance values for this kind of qualitative sub-criteria via pair comparisons between the best micro-grid planning program and others and between others and the worst micro-grid planning program in accordance with the opinions expressed by five experts. These experts are selected from micro-grid operation DMs, and scholars researching micro-grid planning.

Step 3: Standardize the original performance values. With the aim of obtaining accurate assessment results, various units and dimensions of performance values need to be eliminated via a standardizing step. This investigation employs 'rewarding superior performance and punishing inferior performance' standardizing method to normalize performance values of sub-criteria [52]. For the maximum attribute sub-criteria, they can be standardized by:

$$
e_{i j}=\frac{x_{i j}-\frac{1}{m} \sum_{j=1}^{m} x_{i j}}{\max \left\{\max _{j}\left(x_{i j}\right)-\frac{1}{m} \sum_{j=1}^{m} x_{i j}, \frac{1}{m} \sum_{j=1}^{m} x_{i j}-\min _{j}\left(x_{i j}\right)\right\}}
$$

where $e_{i j}$ represents the standardized value of the $i$ th sub-criterion for evaluated micro-grid planning program $j$. 
For minimum type sub-criteria, they can be standardized by:

$$
e_{i j}=\frac{\frac{1}{m} \sum_{j=1}^{m} x_{i j}-x_{i j}}{\max \left\{\max _{j}\left(x_{i j}\right)-\frac{1}{m} \sum_{j=1}^{m} x_{i j}, \frac{1}{m} \sum_{j=1}^{m} x_{i j}-\min _{j}\left(x_{i j}\right)\right\}}
$$

Step 4: Identify the positive and negative reference values for every sub-criterion. The reference values are critical in decision, as DM pays more attention on the disparity between expectations and real results. Considering the theory of Technique for Order Preference by Similarity to an Ideal Solution (TOPSIS) approach, this investigation selects the positive ideal solution (PIS) and the negative ideal solution (NIS) to be the reference values which can reflect the attitudes of DM confronting with risks. If the reference values sequence is PIS, DMs are risk seekers as they are facing losses. While if the reference values sequence is NIS, DMs are risk aversion as they can obtain benefits. The PIS is expressed as $R^{+}=\left\{r_{1}^{+}, r_{2}^{+}, \ldots, r_{n}^{+}\right\}$, where $r_{i}^{+}=\max _{j}\left(e_{i j}\right)$, and the NIS is represented by $R^{-}=\left\{r_{1}^{-}, r_{2}^{-}, \ldots, r_{n}^{-}\right\}$, where $r_{i}^{-}=\min _{j}\left(e_{i j}\right)$.

Step 5: Calculate the values based on value function. In accordance with the selected PIS and NIS, the value function can be calculated as:

$$
v\left(e_{i j}\right)= \begin{cases}\left(1-\xi_{i j}\right)^{\alpha} & \text { if } R^{-} \text {is the reference point } \\ -\lambda\left[-\left(\xi_{i j}{ }^{+}-1\right)\right]^{\beta} & \text { if } R^{+} \text {is the reference point }\end{cases}
$$

where $\xi_{i j}^{-}$and $\xi_{i j}^{+}$can be calculated as:

$$
\begin{aligned}
\xi_{i j}^{-} & =\frac{\min _{i} \min _{j}\left|e_{i j}-r_{i}^{-}\right|+\rho \max _{i} \max _{j}\left|e_{i j}-r_{i}^{-}\right|}{\left|e_{i j}-r_{i}^{-}\right|+\rho \max _{i} \max _{j}\left|e_{i j}-r_{i}^{-}\right|} \\
\xi_{i j}^{+} & =\frac{\min _{i} \min _{j}\left|e_{i j}-r_{i}^{+}\right|+\rho \max _{i} \max _{j}\left|e_{i j}-r_{i}^{+}\right|}{\left|e_{i j}-r_{i}^{+}\right|+\rho \max _{i} \max _{j}\left|e_{i j}-r_{i}^{+}\right|}
\end{aligned}
$$

Generally, $\rho=0.5$. Therefore, the positive prospect values are obtained by $V^{+}=\left(v_{i j}^{+}\right)_{n \times m}=$ $\left(1-\xi_{i j}{ }^{-}\right)^{\alpha}$, and the negative prospect values are obtained by $V^{-}=\left(v_{i j}^{-}\right)_{n \times m}=-\lambda\left[-\left(\xi_{i j}{ }^{+}-1\right)\right]^{\beta}$.

Step 6: Compute the weights of sub-criteria integrating subjective weights determined by the BWM and objective weights calculated by entropy weighting method. To synthetically take experts' preferences and actual data into consideration, subjective weights are identified by the five experts through comparing the significant degree between the best sub-criterion and others and between others and the worst one based on the BWM, and objective weights are computed by entropy weighting method through collecting data of objective sub-criteria and the evaluated values of subjective sub-criteria assigned by the BWM. The final hybrid weights of sub-criteria are obtained via calculating the average values of the objective weights and subjective weights.

Step 7: Calculate the grey cumulative prospect weights. In accordance with Equation (12) and the integrated weights determined by the BWM and entropy weighting method, the grey cumulative prospect weights $\pi^{+}\left(w_{i}\right)$ (taking $R^{-}$as the reference sequence) and $\pi^{-}\left(w_{i}\right)$ (taking $R^{+}$as the reference sequence) are calculated. 
Step 8: Obtain the integrated grey prospect value for each evaluated micro-grid planning program. Since the grey cumulative prospect weights are calculated, the integrated grey prospect value for each evaluated micro-grid planning program is calculated by:

$$
V_{j}=\sum_{i=1}^{n} v_{i j}^{+} \pi^{+}\left(w_{i}\right)+\sum_{i=1}^{n} v_{i j}^{-} \pi^{-}\left(w_{i}\right)
$$

In accordance with the integrated grey prospect value for each evaluated micro-grid planning program, the evaluated micro-grid planning program with the greatest score will be selected as the optimal micro-grid planning program.

The procedure of the established MCDM model for selecting the optimal micro-grid planning program is illustrated as Figure 1.

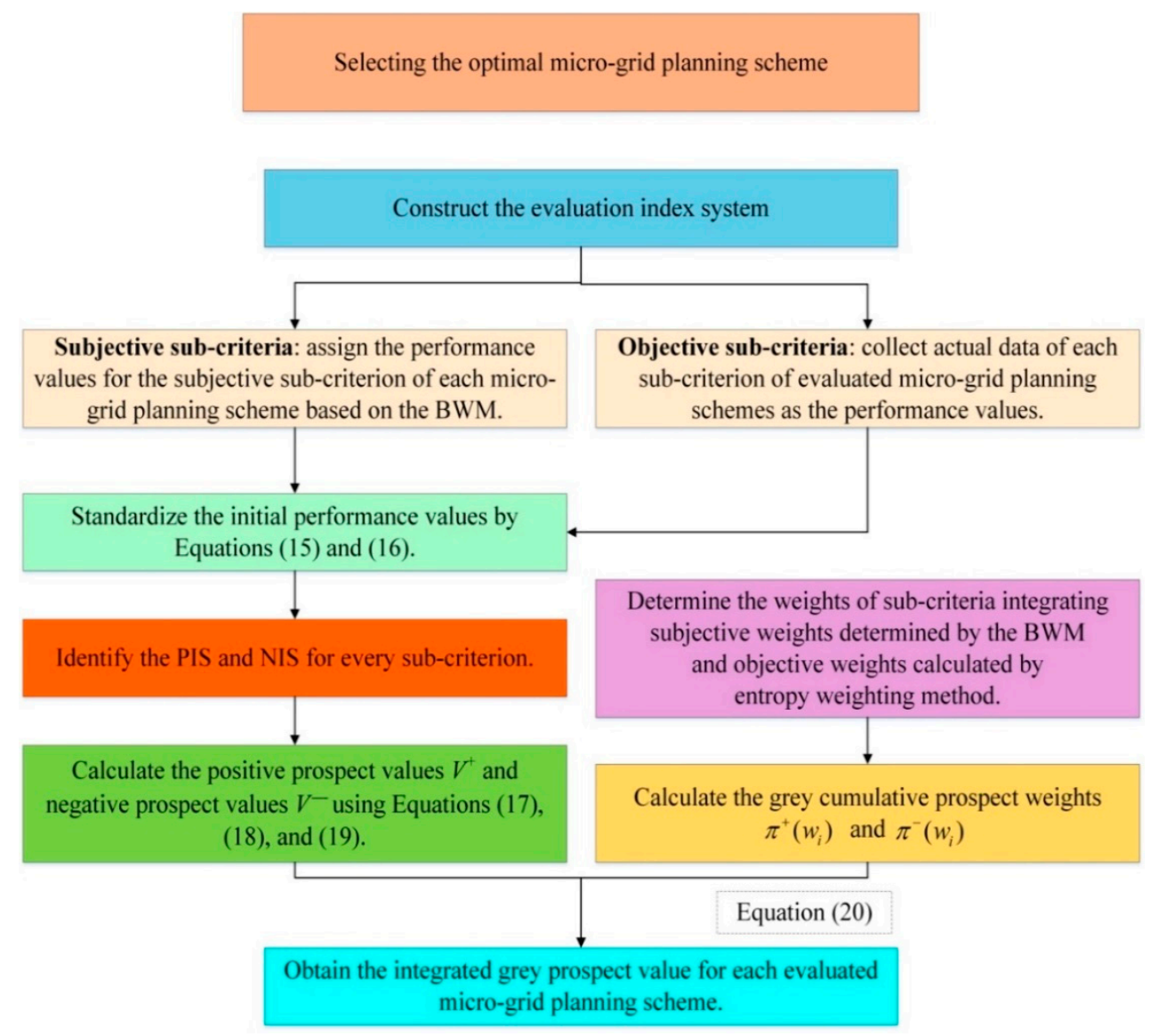

Figure 1. The procedure of the established multi-criteria decision making (MCDM) model for selecting the optimal micro-grid planning program.

\section{Construct the Evaluation Index System for Micro-Grid Planning Programs Evaluation}

Considering that the micro-grid aims at achieving safety, reliable, high efficient, economic, and sustainable operation goals, the evaluation index system is built from the perspectives of economy, electricity supply reliability, and environmental protection $[28,53]$ to reflect the goals of micro-grid systems. Based on the comprehensive evaluation index system, the established MCDM model can comprehensively evaluate the performance of micro-grid planning programs. 18 sub-criteria and their attributes are illustrated in Figure 2. 


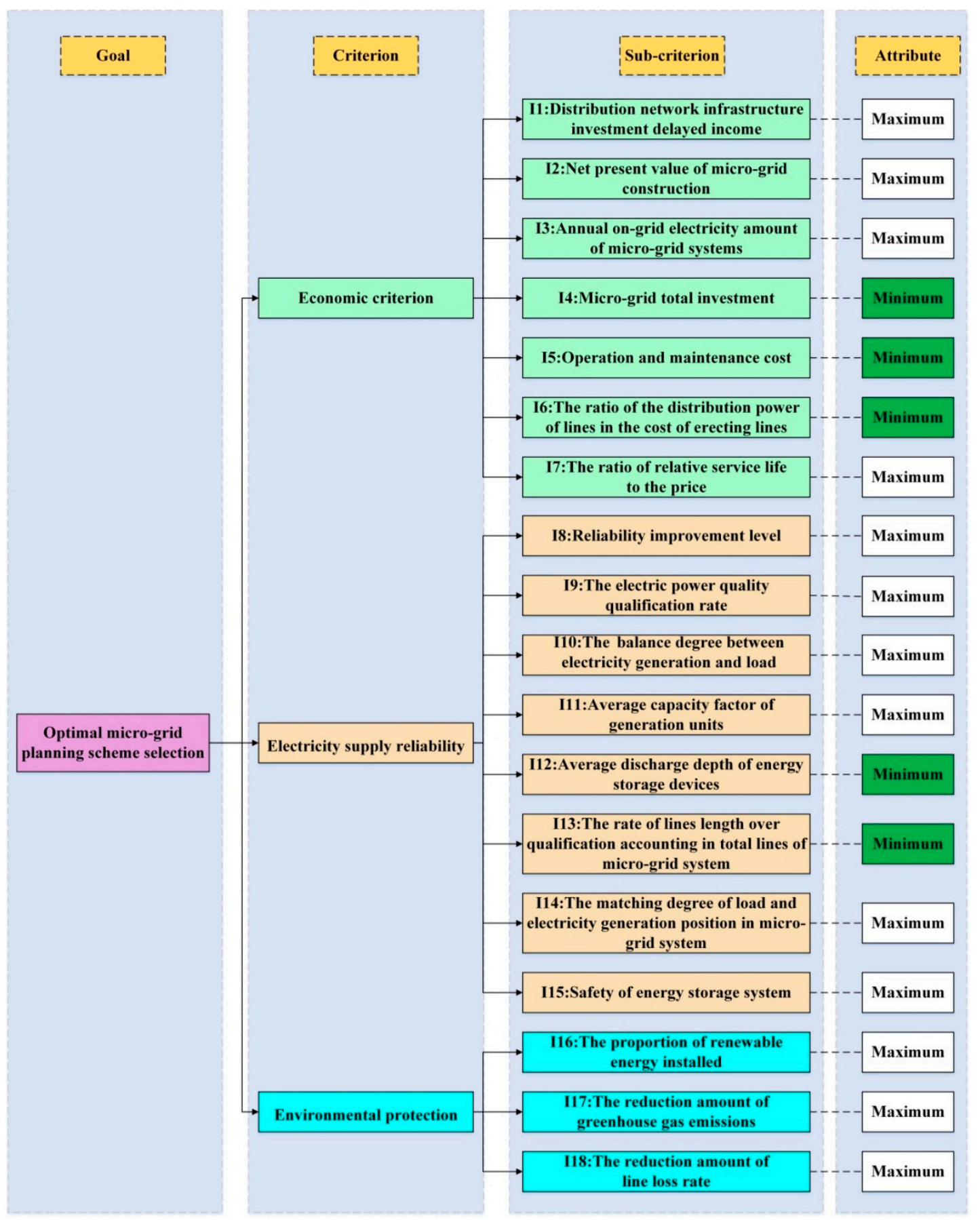

Figure 2. The constructed evaluation index system for the optimal micro-grid planning program selection.

\subsection{Economic Criterion}

The economic criterion of the micro-grid is a vital point to be considered at the planning stage. For distribution network infrastructure investment delayed income, the micro-grid constructed in the load intensive areas can effectively relieve the load demand. Meanwhile, the connection of micro-grid to electricity distributed system can effectively reduce the requirement for distribution network capacity during the peak period of electricity consumption, thus the construction of micro-grids can delay the investment and construction of power grids. This sub-criterion is calculated as:

$$
V_{D I}=P_{M G} C_{E X I}
$$


where $V_{D I}$ represents the distribution network infrastructure investment delayed income, $P_{M G}$ is the distribution capacity of the micro-grid, and $C_{E X I}$ indicates the investment on the unit capacity of the distribution network expansion.

The net present value (NPV) of micro-grid construction and annual on-grid electricity amount of micro-grid systems can reflect the profitability of the constructed micro-grid. The annual on-grid electricity amount of micro-grid systems refers to the amount of electricity generated by micro-grid systems sold to electricity grid enterprises. For the micro-grid total investment, it is made up of construction cost, original equipment cost, and installation cost of micro-grid. Operation and maintenance cost refers to the cost of the stable operation and maintenance of electricity generation equipment, energy storage equipment, transformers, and distribution lines in the micro-grid systems.

For the ratio of the distribution power of lines in the cost of erecting lines, it is employed to evaluate the utilization efficiency of lines. The transmission lines in the micro-grid are complicated, and some of the transmission lines are expensive and difficult to erect, which have relatively low transmission efficiency. Hence these lines are inefficient and redundant which should be removed from the optimal micro-grid planning program. The ratio of the investment to the current flow is defined as:

$$
t=\frac{P}{I}
$$

where $P$ implies the distribution power of the line, and $I$ indicates the cost for erecting this line. According to the standard of the ratio of the investment to the current flow [53], we suppose the amount of the lines with the ratios of the investment to the current flow less than the standard to be $n$. Suppose that the total amount of lines in the micro-grid is $m$, the ratio of the distribution power of lines in the cost of erecting lines can be simply calculated as $n / m$. The ratio of relative service life to the price is utilized to assess the economic efficiency of energy storage systems. The more its value is, the more economic the energy storage system will be.

\subsection{Electricity Supply Reliability Criterion}

For reliability improvement level, since the integration and application of micro-grid systems can satisfy the electricity consumption at peak periods and distribute electricity to remote areas, the reliability of the electricity supply can be improved. It measures the reliability improvement level after the integration of micro-grid systems compared with an electricity grid network without micro-grid systems integration. It is evaluated by the changes of average electricity outage time of the system. For the electric power quality qualification rate, it refers to the ratio of the amount of qualified monitoring points for electricity quality to the total amount of monitoring points, and the greater the value is, the higher the qualified ratio becomes.

The degree of balance between electricity generation and load measures whether the electricity generation capacity can adapt to the changes of load per hour. The construction of the micro-grid not simply increases electricity generation, but fully uses renewable energy based electricity generation to satisfy the demand of electricity at peak load and to store excess power at valley loads. It is computed as:

$$
\eta=\lim _{\Delta t \rightarrow 0} \sum_{i=0}^{n}\left|P_{G i}-P_{L i}\right| \Delta t=\int_{0}^{i}\left|P_{G i}-P_{L i}\right| d t
$$

where $\eta$ is the balance degree between electricity generation and load, $P_{G i}$ represents the electricity generation amount at $i$ time point, and $P_{L i}$ indicates the electricity consumption amount at the $i$ time point.

For the average capacity factor of generation units, it represents the ratio of the actual generating capacity to the specified electricity generation capacity of generating units. The greater the average capacity factor is, the higher the utilization ratio of the generating units will be. For the average discharge depth of energy storage devices, it has a great influence on battery life which will affect the 
energy storage ability and the electricity supply reliability [54]. The lower the average discharge depth of energy storage device is, the longer the battery life will be.

For the rate of lines length over qualification accounting in total lines of micro-grid system, it means that if the electricity supply lines are too long, the terminal voltage problem will be caused which will result in insufficient electricity supply. It is calculated via dividing the amount of total power supply lines in the micro-grid by the amount of lines whose length exceed the qualification.

For the matching degree of load and electricity generation position in micro-grid system, it reflects the rationality of the distribution position of electricity generation and load. It determines the site of distribution generation which will influence electricity generation capacity. It is measured by:

$$
K=\sum_{i=1}^{n} \sum_{j=1}^{m} d_{i j} l_{j}
$$

where $n$ represents the amount of distributed electricity generation, $m$ means the amount of centralized electricity consuming areas, $d_{i j}$ is the length of the electricity supply lines from distributed electricity generation to centralized electricity consuming areas, and $i_{j}$ is the load of $j$ centralized electricity consuming area.

For safety of energy storage system, it is a qualitative sub-criterion measuring the ability of energy storage system to maintain stability and safe operation under the impact of external environment changes.

\subsection{Environmental Protection Criterion}

With the aggravation of air pollution and natural resources, the environmental protection effects provided by micro-grids have gradually received more attention. The proportion of renewable energy installed and the reduction amount of greenhouse gas emissions are applied to evaluate the environmental protection performance of micro-grid. For the reduction amount of line loss rate, the construction of micro-grid avoids the high line loss rate caused by long-distance transmission and distribution. Therefore, the reduction amount of line loss rate is measured by the variation of line loss rate of large electricity network before and after micro-grid construction.

\section{Empirical Process for Prioritizing Micro-Grid Planning Programs}

Empirical analysis is conducted in this section to prioritize micro-grid planning programs employed the established novel MCDM model. Hybrid optimization model for electric renewable (HOMER) software, developed by the new energy laboratory in the United States to design and optimize small distributed generation systems, is employed to optimize the configuration of micro-power supply and energy storage devices in the micro-grid [53,55]. The micro power sources selected in this paper are micro gas turbine, photovoltaic power generation unit and wind power generation unit, and the types of energy storage devices are lithium-ion (Li-ion) batteries, sodium-sulfur (NaS) batteries, and lithium iron phosphate (LIP) batteries. With the aim of verifying the effectiveness and practicability of the index system and the established MCDM model, this paper uses HOMER software to optimize three different micro-grid planning programs (displayed in Table 2) [53], and selects the optimum program through evaluating the performance of three programs. The prioritizing results will provide compelling reference for DM to select the optimal program for micro-grid construction. The empirical process is conducted following the steps below. 
Table 2. Three micro-grid planning programs.

\begin{tabular}{ccccc}
\hline Program & $\begin{array}{c}\text { Micro Gas } \\
\text { Turbine }\end{array}$ & $\begin{array}{c}\text { Photovoltaic Power } \\
\text { Generation Unit }\end{array}$ & $\begin{array}{c}\text { Wind Power } \\
\text { Generation Unit }\end{array}$ & Energy Storage System \\
\hline M1 & $30 \mathrm{~kW}$ & $80 \mathrm{kWp}$ & - & Li-ion battery $350 \mathrm{kWh}$ \\
M2 & - & $100 \mathrm{kWp}$ & $200 \mathrm{~kW}$ & NaS battery 600 $\mathrm{kWh}$ \\
M3 & $10 \mathrm{~kW}$ & $150 \mathrm{kWp}$ & - & LIP battery $800 \mathrm{kWh}$ \\
\hline
\end{tabular}

\subsection{Determine the Evaluated Values of the Subjective Sub-Criterion}

Since the constructed assessment index system contains a subjective sub-criterion that is safety of energy storage system, the performance values of the subjective sub-criterion of three planning programs are determined by the BWM according to the judgments of five experts.

Firstly, five experts select the best and the worst micro-grid planning programs. The best one has a superior performance over others with regard to the subjective sub-criterion, while the worst one is contrary. The best and the worst micro-grid planning programs identified by five experts are shown in Table 3.

Table 3. The best and the worst micro-grid planning programs of safety of energy storage system selected by 5 experts.

\begin{tabular}{ccccccc}
\hline Qualitative Sub-Criteria & Expert Number & $\mathbf{1}$ & $\mathbf{2}$ & $\mathbf{3}$ & $\mathbf{4}$ & $\mathbf{5}$ \\
\hline Safety of energy storage & The best program & M1 & M2 & M1 & M1 & M2 \\
system & The worst program & M3 & M3 & M3 & M3 & M3 \\
\hline
\end{tabular}

Secondly, the comparison results between the best micro-grid planning program and others and between others and the worst micro-grid planning program should be determined utilizing the number in the interval of $[1,9]$ considering the experts' judgments. The comparison results are shown in Tables 4 and 5.

Table 4. Compared results of the best micro-grid planning program over others.

\begin{tabular}{ccccc}
\hline Expert Number & The Best Micro-Grid & M1 & M2 & M3 \\
\hline 1 & M1 & 1 & 4 & 9 \\
2 & M2 & 5 & 1 & 9 \\
3 & M1 & 1 & 5 & 9 \\
4 & M1 & 1 & 3 & 9 \\
5 & M2 & 6 & 1 & 9 \\
\hline
\end{tabular}

Table 5. Compared results of other micro-grid planning programs over the worst one.

\begin{tabular}{cccccc}
\hline Expert Number & $\mathbf{1}$ & $\mathbf{2}$ & $\mathbf{3}$ & $\mathbf{4}$ & $\mathbf{5}$ \\
\hline The worst micro-grid & M3 & M3 & M3 & M3 & M3 \\
M1 & 9 & 5 & 9 & 9 & 4 \\
M2 & 6 & 9 & 5 & 7 & 9 \\
M3 & 1 & 1 & 1 & 1 & 1 \\
\hline
\end{tabular}

Thirdly, the comparing results listed in Tables 4 and 5 are substituted into Equation (4) to obtain the performance values of three micro-grid planning program for safety of energy storage system 
sub-criterion. Taking the opinions of Expert 1 as an example, through substituting comparing results into Equation (4), we can obtain:

$$
\begin{gathered}
\min \xi \\
\text { s.t. } \\
\left|w_{1}-w_{1}\right| \leq \xi,\left|w_{1}-4 w_{2}\right| \leq \xi\left|w_{1}-9 w_{3}\right| \leq \xi \\
\left|w_{1}-9 w_{3}\right| \leq \xi\left|w_{2}-6 w_{3}\right| \leq \xi\left|w_{3}-w_{3}\right| \leq \xi \\
w_{1}+w_{2}+w_{3}=1 \\
w_{1} \geq 0, w_{2} \geq 0, w_{3} \geq 0
\end{gathered}
$$

Then, the performance values of three micro-grid planning programs for safety of energy storage system sub-criterion are obtained through calculating the average values of the results based on experts' judgments. The performance values and the consistent examination results are illustrated in Table 6 . Since the coherent ratios are close to 0 , the comparing results are coherent and validity.

Table 6. Performance values of three micro-grid planning programs of safety of energy storage system.

\begin{tabular}{ccccccc}
\hline \multirow{2}{*}{ Program } & \multicolumn{5}{c}{ Expert } & \multirow{2}{*}{ Average Value } \\
\cline { 2 - 5 } & Expert 1 & Expert 2 & Expert 3 & Expert 4 & Expert 5 & \\
\hline M1 & 0.7187 & 0.1809 & 0.7524 & 0.6706 & 0.1518 & 0.4949 \\
M2 & 0.2188 & 0.7524 & 0.1809 & 0.2706 & 0.7768 & 0.4399 \\
M3 & 0.0625 & 0.0667 & 0.0667 & 0.0588 & 0.0714 & 0.0652 \\
$\xi^{*}$ & 0.1563 & 0.1524 & 0.1524 & 0.1412 & 0.1339 & 0.1472 \\
CR & 0.0299 & 0.0291 & 0.0291 & 0.0270 & 0.0256 & 0.0282 \\
\hline
\end{tabular}

\subsection{Standardize the Original Performance Values}

Based on the optimization results of three micro-grid planning programs obtained by HOMER software [53], we can obtain the performance values of quantitative sub-criteria of three programs. Thus, the initial performance values of all sub-criteria of three micro-grid planning programs can be obtained. To eliminate the influences of dimensions and units of sub-criteria on evaluation results, we need to standardize the initial performance values via Equations (15) and (16) to obtain the normalization decision matrix $E$, which is listed as below:

$$
E=\left[\begin{array}{ccc}
-0.6765 & 1 & -0.3235 \\
-0.3517 & 1 & -0.6483 \\
-1 & 0.6553 & 0.3447 \\
1 & -0.3019 & -0.6981 \\
1 & -0.2479 & -0.7522 \\
-0.7143 & 1 & -0.2857 \\
1 & -0.4571 & -0.5429 \\
-0.8213 & 1 & -0.1787 \\
1 & -0.2000 & -0.8000 \\
-1 & 0.8000 & 0.2000 \\
1 & -0.6471 & -0.3529 \\
-0.2000 & 1 & -0.8000 \\
-1 & 0.1250 & 0.8750 \\
1 & -0.8331 & -0.1670 \\
0.6025 & 0.3975 & -1 \\
-1 & 0.5 & 0.5 \\
-1 & 0.3078 & 0.6922 \\
0 & -1 & 1
\end{array}\right]
$$




\subsection{Identify the NIS and PIS Reference Values of Every Sub-Criterion}

To select the optimal micro-grid planning program using GCPT, it is of great significance to pick out the NIS and PIS reference sequences of every sub-criterion. Based on the normalization decision matrix $E$, the PIS reference sequence $R^{+}$and NIS reference sequence $R^{-}$are selected as:

$$
\begin{gathered}
R^{+}=[1,1,0.6553,1,1,1,1,1,1,0.8000,1,1,0.8750,1,0.6025,0.5000,0.6922,1] \\
R^{-}=\left[\begin{array}{c}
-0.6765,-0.6483,-1,-0.6981,-0.7522,-0.7143,-0.5429,-0.8213, \\
-0.8000,-1,-0.6471,-0.8000,-1,-0.8331,-1,-1,-1,-1]
\end{array}\right.
\end{gathered}
$$

\subsection{Calculate the Prospect Values Based on Value Function}

After selecting the PIS and NIS reference sequences, the prospect values in accordance with the value function can be calculated. Firstly, the grey correlation degree $\xi_{i j}^{+}$between $e_{i j}$ and $R^{+}$, and $\xi_{i j}^{-}$between $e_{i j}$ and $R^{-}$in accordance with Equations (18) and (19) can be calculated, which are illustrated as:

$$
\xi_{i j}^{+}=\left[\begin{array}{ccc}
0.3736 & 1 & 0.4304 \\
0.4252 & 1 & 0.3776 \\
0.3766 & 1 & 0.7630 \\
1 & 0.4344 & 0.3706 \\
1 & 0.4449 & 0.3634 \\
0.3684 & 1 & 0.4375 \\
1 & 0.4070 & 0.3933 \\
0.3544 & 1 & 0.4590 \\
1 & 0.4545 & 0.3571 \\
0.3571 & 1 & 0.6250 \\
1 & 0.3778 & 0.4250 \\
0.4545 & 1 & 0.3571 \\
0.3478 & 0.5714 & 1 \\
1 & 0.3530 & 0.4615 \\
1 & 0.8298 & 0.3842 \\
0.4 & 1 & 1 \\
0.3714 & 0.7224 & 1 \\
0 & 0.3333 & 1
\end{array}\right]
$$




$$
\xi_{i j}^{-}=\left[\begin{array}{ccc}
1 & 0.3736 & 0.7391 \\
0.7713 & 0.3776 & 1 \\
1 & 0.3766 & 0.4265 \\
0.3706 & 0.7162 & 1 \\
0.3634 & 0.6648 & 1 \\
1 & 0.3684 & 0.7 \\
0.3933 & 0.9211 & 1 \\
1 & 0.3544 & 0.6088 \\
0.3571 & 0.6250 & 1 \\
1 & 0.3571 & 0.4545 \\
0.3778 & 1 & 0.7727 \\
0.6250 & 0.3571 & 1 \\
1 & 0.4706 & 0.3478 \\
0.3530 & 1 & 0.6002 \\
0.3842 & 0.4171 & 1 \\
1 & 0.4 & 0.4 \\
1 & 0.4333 & 0.3714 \\
0.5 & 1 & 0.3333
\end{array}\right]
$$

Then, the prospective values $V^{+}$and $V^{-}$can be obtained via Equation (17), which are listed as:

$$
V^{+}=\left[\begin{array}{ccc}
0 & 0.6625 & 0.3065 \\
0.2730 & 0.6588 & 0 \\
0 & 0.6598 & 0.6131 \\
0.6653 & 0.3301 & 0 \\
0.6721 & 0.3822 & 0 \\
0 & 0.6674 & 0.3466 \\
0.6442 & 0.1071 & 0 \\
0 & 0.6804 & 0.4379 \\
0.6779 & 0.4218 & 0 \\
0 & 0.6779 & 0.5866 \\
0.6587 & 0 & 0.2715 \\
0.4218 & 0.6779 & 0 \\
0 & 0.5714 & 0.6865 \\
0.6817 & 0 & 0.4463 \\
0.6527 & 0.6219 & 0 \\
0 & 0.6379 & 0.6379 \\
0 & 0.6067 & 0.6646 \\
0.5434 & 0 & 0.6999
\end{array}\right]
$$




$$
V^{-}=\left[\begin{array}{ccc}
-1.4907 & 0 & -1.3712 \\
-1.3821 & 0 & -1.4824 \\
-1.4845 & 0 & -0.6338 \\
0 & -1.3626 & -1.4970 \\
0 & -1.3405 & -1.5122 \\
-1.5016 & 0 & -1.3561 \\
0 & -1.4207 & -1.4495 \\
-1.5308 & 0 & -1.3104 \\
0 & -1.3199 & -1.5252 \\
-1.5252 & 0 & -0.9491 \\
0 & -1.4820 & -1.3826 \\
-1.3198 & 0 & -1.5252 \\
-1.5446 & -1.0675 & 0 \\
0 & -1.5339 & -1.3051 \\
0 & -0.4735 & -1.4685 \\
-1.4353 & 0 & 0 \\
-1.4953 & -0.7285 & 0 \\
-1.2226 & -1.5748 & 0
\end{array}\right]
$$

\subsection{Calculate the Grey Cumulative Prospect Weights}

To calculate the grey cumulative prospect weights, we firstly need to compute the integrated weights of sub-criteria integrating the subjective weights determined by the BWM and objective weights computed by the entropy weighting approach.

\subsubsection{The Subjective Weights Determined by the BWM}

Firstly, the best and the worst sub-criteria need to be selected by five experts which are demonstrated in Table 7.

Table 7. The best and the worst sub-criteria selected by five experts.

\begin{tabular}{ccc}
\hline Expert Number & The Best Sub-Criteria & The Worst Sub-Criteria \\
\hline 1 & Annual on-grid electricity amount of micro-grid system & The reduction amount of line loss rate \\
2 & NPV of micro-grid construction & The reduction amount of line loss rate \\
3 & The electric power quality qualification rate & The reduction amount of line loss rate \\
4 & The reduction amount of greenhouse gas emissions & The reduction amount of line loss rate \\
5 & The proportion of renewable energy installed & The reduction amount of line loss rate \\
\hline
\end{tabular}

Then, the significance degrees between the best sub-criterion and others and between others and the worst one need to be identified by experts via assigning a value in the interval of $[1,9]$. The results are listed in Tables 8 and 9. 
Table 8. The significant degree between the best sub-criterion and others.

\begin{tabular}{cccccc}
\hline Expert Number & $\mathbf{1}$ & $\mathbf{2}$ & $\mathbf{3}$ & $\mathbf{4}$ & $\mathbf{5}$ \\
\hline The Best Sub-Criteria & I3 & I2 & I9 & I17 & I16 \\
\hline I1 & 2 & 2 & 3 & 3 & 4 \\
I2 & 2 & 1 & 3 & 3 & 4 \\
I3 & 1 & 2 & 2 & 3 & 2 \\
I4 & 2 & 3 & 3 & 4 & 4 \\
I5 & 2 & 3 & 3 & 4 & 6 \\
I6 & 3 & 3 & 5 & 8 & 6 \\
I7 & 3 & 3 & 5 & 8 & 6 \\
I8 & 4 & 6 & 2 & 7 & 5 \\
I9 & 4 & 6 & 1 & 4 & 5 \\
I10 & 5 & 7 & 8 & 7 & 7 \\
I11 & 5 & 7 & 8 & 7 & 7 \\
I12 & 7 & 7 & 6 & 9 & 7 \\
I13 & 6 & 8 & 7 & 6 & 8 \\
I14 & 6 & 8 & 7 & 6 & 8 \\
I15 & 3 & 5 & 6 & 5 & 3 \\
I16 & 9 & 4 & 4 & 2 & 1 \\
I17 & 8 & 4 & 4 & 1 & 3 \\
I18 & 9 & 9 & 9 & 9 & 9 \\
\hline
\end{tabular}

Table 9. The significant degree between others and the worst sub-criterion.

\begin{tabular}{cccccc}
\hline Expert Number & $\mathbf{1}$ & $\mathbf{2}$ & $\mathbf{3}$ & $\mathbf{4}$ & $\mathbf{5}$ \\
\hline The Worst Sub-Criteria & $\mathbf{I 1 8}$ & $\mathbf{I 1 8}$ & $\mathbf{I 1 8}$ & $\mathbf{I 1 8}$ & $\mathbf{I 1 8}$ \\
\hline I1 & 8 & 8 & 7 & 7 & 6 \\
I2 & 8 & 9 & 7 & 7 & 6 \\
I3 & 9 & 8 & 8 & 7 & 8 \\
I4 & 8 & 7 & 7 & 6 & 6 \\
I5 & 8 & 7 & 7 & 6 & 4 \\
I6 & 7 & 7 & 5 & 2 & 4 \\
I7 & 7 & 7 & 5 & 2 & 4 \\
I8 & 6 & 4 & 8 & 3 & 5 \\
I9 & 6 & 4 & 9 & 6 & 5 \\
I10 & 5 & 3 & 2 & 3 & 3 \\
I11 & 5 & 3 & 2 & 3 & 3 \\
I12 & 3 & 3 & 4 & 1 & 3 \\
I13 & 4 & 2 & 3 & 4 & 2 \\
I14 & 4 & 2 & 3 & 4 & 2 \\
I15 & 7 & 5 & 4 & 5 & 7 \\
I16 & 1 & 6 & 6 & 8 & 9 \\
I17 & 2 & 6 & 6 & 9 & 7 \\
I18 & 1 & 1 & 1 & 1 & 1 \\
\hline
\end{tabular}

The significance degree results are substituted into Equation (4). Through solving the formula via Lingo 9 software, the optimal weights determined by the BWM can be obtained which are displayed in Table 10. The final subjective weights of sub-criteria are obtained via calculating the mean values of the results of five experts with regard to every sub-criterion. Through calculating the CR using Equation (5), it is discovered that the values of CR are close to 0 which indicates that the comparing results are consistent. 
Table 10. Optimal subjective weights and CR.

\begin{tabular}{|c|c|c|c|c|c|c|}
\hline $\begin{array}{l}\text { Expert Number } \\
\text { Sub-Criterion }\end{array}$ & E1 & E2 & E3 & E4 & E5 & $\begin{array}{l}\text { Average } \\
\text { Weight }\end{array}$ \\
\hline $\begin{array}{l}\text { Distribution network infrastructure } \\
\text { investment delayed income }\end{array}$ & 0.0908 & 0.1013 & 0.0667 & 0.0746 & 0.0570 & 0.0781 \\
\hline NPV of micro-grid construction & 0.0908 & 0.1663 & 0.0667 & 0.0746 & 0.0570 & 0.0911 \\
\hline $\begin{array}{l}\text { Annual on-grid electricity amount of } \\
\text { micro-grid system }\end{array}$ & 0.1492 & 0.1013 & 0.1001 & 0.0746 & 0.1138 & 0.1078 \\
\hline Micro-grid total investment & 0.0908 & 0.0675 & 0.0667 & 0.0560 & 0.0570 & 0.0676 \\
\hline Operation and maintenance cost & 0.0908 & 0.0675 & 0.0667 & 0.0560 & 0.0380 & 0.0638 \\
\hline $\begin{array}{l}\text { The ratio of the distribution power of lines in } \\
\text { the cost of erecting lines }\end{array}$ & 0.0606 & 0.0675 & 0.0400 & 0.0280 & 0.0380 & 0.0468 \\
\hline The ratio of relative service life to the price & 0.0606 & 0.0675 & 0.0400 & 0.0280 & 0.0380 & 0.0468 \\
\hline Reliability improvement level & 0.0454 & 0.0338 & 0.1001 & 0.0320 & 0.0456 & 0.0514 \\
\hline The electric power quality qualification rate & 0.0454 & 0.0338 & 0.1644 & 0.0560 & 0.0456 & 0.0690 \\
\hline $\begin{array}{l}\text { The balance degree between electricity } \\
\text { generation and load }\end{array}$ & 0.0363 & 0.0289 & 0.0250 & 0.0320 & 0.0325 & 0.0309 \\
\hline Average capacity factor of generation units & 0.0363 & 0.0289 & 0.0250 & 0.0320 & 0.0325 & 0.0309 \\
\hline $\begin{array}{l}\text { Average discharge depth of energy } \\
\text { storage devices }\end{array}$ & 0.0260 & 0.0289 & 0.0334 & 0.0249 & 0.0325 & 0.0291 \\
\hline $\begin{array}{l}\text { The rate of lines length over qualification } \\
\text { accounting in total lines of micro-grid system }\end{array}$ & 0.0303 & 0.0253 & 0.0286 & 0.0373 & 0.0285 & 0.0300 \\
\hline $\begin{array}{l}\text { The matching degree of load and electricity } \\
\text { generation position in micro-grid system }\end{array}$ & 0.0303 & 0.0253 & 0.0286 & 0.0373 & 0.0285 & 0.0300 \\
\hline Safety of energy storage system & 0.0605 & 0.0405 & 0.0334 & 0.0448 & 0.0760 & 0.0510 \\
\hline The proportion of renewable energy installed & 0.0202 & 0.0506 & 0.0501 & 0.1120 & 0.1872 & 0.0840 \\
\hline $\begin{array}{l}\text { The reduction amount of greenhouse } \\
\text { gas emissions }\end{array}$ & 0.0227 & 0.0506 & 0.0501 & 0.1839 & 0.0760 & 0.0767 \\
\hline The reduction amount of line loss rate & 0.0130 & 0.0145 & 0.0144 & 0.0160 & 0.0163 & 0.0148 \\
\hline$\xi^{*}$ & 0.0324 & 0.0362 & 0.0357 & 0.0399 & 0.0407 & 0.0370 \\
\hline CR & 0.0062 & 0.0069 & 0.0068 & 0.0076 & 0.0078 & 0.0071 \\
\hline
\end{tabular}

\subsubsection{The Objective Weights Calculated by the Entropy Weighting Method}

Based on the normalization decision matrix, the objective weights of sub-criteria are computed by the entropy weighting method in accordance with the Formulas (6)-(9), which are listed as:

$$
\begin{array}{r}
w=(0.0654,0.0690,0.0422,0.0630,0.0583,0.0615,0.0917,0.0539,0.0551 \\
\\
0.0437,0.0692,0.0551,0.0449,0.0533,0.0419,0.0417,0.0425,0.0475)
\end{array}
$$

\subsubsection{The Grey Cumulative Prospect Weights}

After obtaining the subjective weights determined by the BWM and objective weights calculated by the entropy weighting approach, the final hybrid weights of sub-criteria can be calculated via assigning the equal significance of the above results. The integrated weights of sub-criteria are listed as:

$$
\begin{aligned}
w^{*}= & (0.0717,0.0800,0.0750,0.0653,0.0610,0.0541,0.0693,0.0526,0.0621, \\
& 0.0373,0.0501,0.0421,0.0375,0.0417,0.0465,0.0628,0.0596,0.0312)
\end{aligned}
$$


Then, in accordance with Equation (12) and the integrated weights determined by the BWM and entropy weighting method, the grey cumulative prospect weights $\pi^{+}\left(w_{i}\right)$ and $\pi^{-}\left(w_{i}\right)$ are calculated, which are presented as:

$$
\begin{aligned}
\pi^{+}\left(w_{i}\right)= & (0.1580,0.1669,0.1616,0.1508,0.1457,0.1371,0.1553,0.1352,0.1469 \\
& 0.1131,0.1317,0.1205,0.1133,0.1198,0.1268,0.1479,0.1439,0.1029) \\
& \\
\pi^{-}\left(w_{i}\right)= & (0.1392,0.1487,0.1430,0.1314,0.1261,0.1171,0.1362,0.1151,0.1274, \\
& 0.0928,0.1115,0.1001,0.0930,0.0994,0.1065,0.1283,0.1242,0.0828)
\end{aligned}
$$

\subsection{Obtain the Integrated Grey Prospect Value for Each Evaluated Micro-Grid Planning Program}

Based on the prospective values $V^{+}$and $V^{-}$and the grey cumulative prospect weights $\pi^{+}\left(w_{i}\right)$ and $\pi^{-}\left(w_{i}\right)$, in accordance with Equation (20), the integrated grey prospect values for the evaluated micro-grid planning programs are obtained. The integrated grey prospect values and the ranking of the evaluated micro-grid planning programs are listed in Table 11. It indicates that the micro-grid planning program M2 with $100 \mathrm{kWp}$ photovoltaic power generation unit, $200 \mathrm{~kW}$ wind power generation unit, and $600 \mathrm{kWh} \mathrm{NaS}$ battery energy storage system is the optimal micro-grid planning program.

Table 11. The integrated grey prospect values and rankings of the evaluated micro-grid planning programs.

\begin{tabular}{cccc}
\hline The Evaluated Micro-Grid Planning Programs & M1 & M2 & M3 \\
\hline $\begin{array}{c}\text { The integrated grey prospect values } \\
\text { Ranking }\end{array}$ & -1.0645 & -0.22563 & -1.52207 \\
\hline
\end{tabular}

\section{Discussion and Sensitivity Analysis}

\subsection{Discussion on Prioritizing Results}

This paper established a novel MCDM model combining the BWM, the entropy weighting method, and GCPT for selecting the optimal micro-grid planning program. Three micro-grid planning programs optimized by HOMER software are treated as the evaluated objects in this research and the planning program with $100 \mathrm{kWp}$ photovoltaic power generation unit, $200 \mathrm{~kW}$ wind power generation unit, and $600 \mathrm{kWh} \mathrm{NaS}$ battery energy storage system is identified to be the optimum program evaluated by the established novel MCDM model. The evaluation results will be further discussed based on the weights determined by the BWM and the entropy weighting method and the performance values of sub-criteria.

For the subjective weights determined by the BWM, experts pay more attention on the sub-criteria attributed to the economic criterion and environmental protection criterion. This is primarily because that the micro-grid concept is proposed aiming at absorbing more renewable energy-based electricity generation, reducing the dependence on thermal power generation and thus reducing the damage to the environment. Therefore, the environmental protection performance of micro-grids gains more attention. The weight of the reduction amount of greenhouse gas emissions is 0.0767 . Additionally, investors also highlight the economic criterion of the micro-grid, and the weights of NPV of micro-grid construction and annual electricity generation amount to network are respectively 0.0911 and 0.1078 . Moreover, the micro-grid should guarantee the electricity supply quality and reliability so that it can be extensively applied in the future. Hence, the significance of the electric power quality qualification rate is also highlighted by experts, the weight of which is 0.0690 .

For the objective weights computed by the entropy weighting approach based on the actual data of three micro-grid planning programs, the sub-criteria attributed to economic and electricity supply reliability perspectives are emphasized. The weights of NPV of micro-grid construction and micro-grid total investment belonging to economic criterion are respectively 0.0690 and 0.0630 . The weight of the electric power quality qualification rate is 0.0621 . 
For the integrated weights integrating the subjective weights determined by the BWM and the objective weights computed by the entropy weighting approach, the distribution network infrastructure investment delayed income, NPV of micro-grid construction, annual electricity generation amount to network, micro-grid total investment, the electric power quality qualification rate, and the proportion of renewable energy installed are the most significant sub-criteria.

The performance values of the micro-grid planning program M2 related to the sub-criteria with high weights are relatively higher than another two programs. For example, the performance value of the NPV of micro-grid construction for M2 is 4.04 million yuan higher than 2.89 million yuan of M1 and 2.64 million yuan of M3. Considering about the superior performance of M2 with regard to some significant sub-criteria, M2 is the optimal program for micro-grid planning.

\subsection{Sensitivity Analysis}

Considering about the GCPT, the risk preferences for selecting the optimum micro-grid planning program are critically reflected by the parameters $\alpha, \beta$ and $\lambda$ in Equation (17). $\lambda$ is a risk aversion coefficient higher than 1 , and the higher the value of $v$, the more sensitive DM is to risk. $\alpha$ and $\beta$ are sensitivity reducing parameters both in the interval of $(0,1) . \alpha$ represents the concavity degree for value function in the gain interval, and $\alpha$ illustrates the convexity degree for value function in the loss interval. The larger the values of $\alpha$ and $\beta$, the less possibly the DM will be to avoid risk. Considering that various risk preferences of DM may lead to different selections, it is necessary to analyze the influences of the changes of parameters values on evaluated programs rankings. The values of $\alpha, \beta$ and $\lambda$ are assumed to be changed in the following scenarios to represent various risk preferences:

- $\quad$ Scenario 1: The value of $\lambda$ changes from 1 to 10 .

- Scenario 2: The value of $\alpha$ changes from 0 to 1 .

- Scenario 3: The value of $\beta$ changes from 0 to 1 .

The trends of integrated prospect values of three micro-grid planning programs computed by various sensitivity analysis scenarios under different risk preferences are demonstrated as Figures 3-5. It is obvious that the rankings of three micro-grid planning programs are not sensitive to the changes of the values of $\alpha, \beta$ and $\lambda$, which demonstrates that no matter what kinds of risk preferences the DM and investors may have, taking the economic criterion, the electricity supply reliability perspective, and the environmental protection aspect into consideration, the optimal micro-grid planning program will not be influenced.

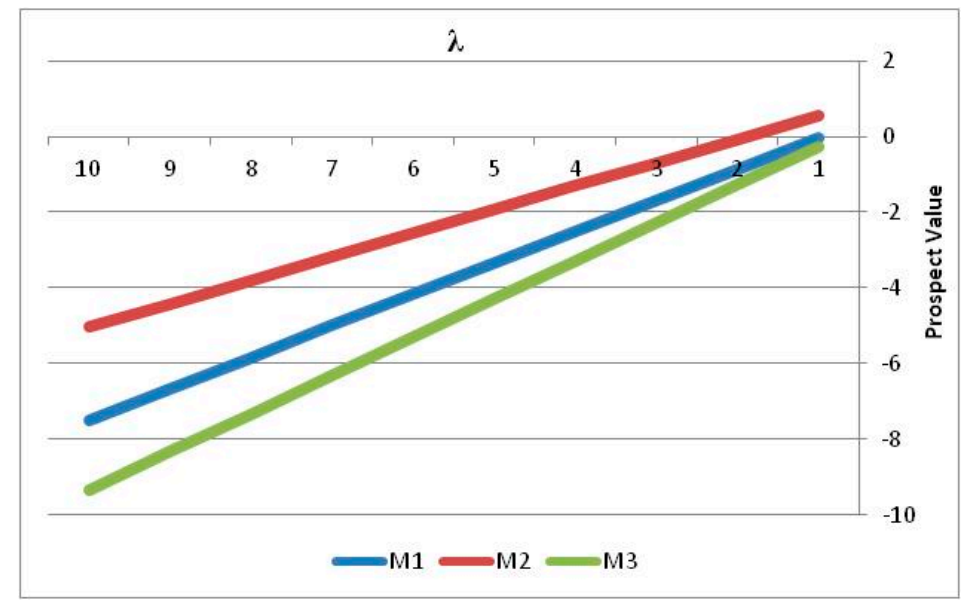

Figure 3. The integrated prospect values of three micro-grid planning programs with different $\lambda$ values. 


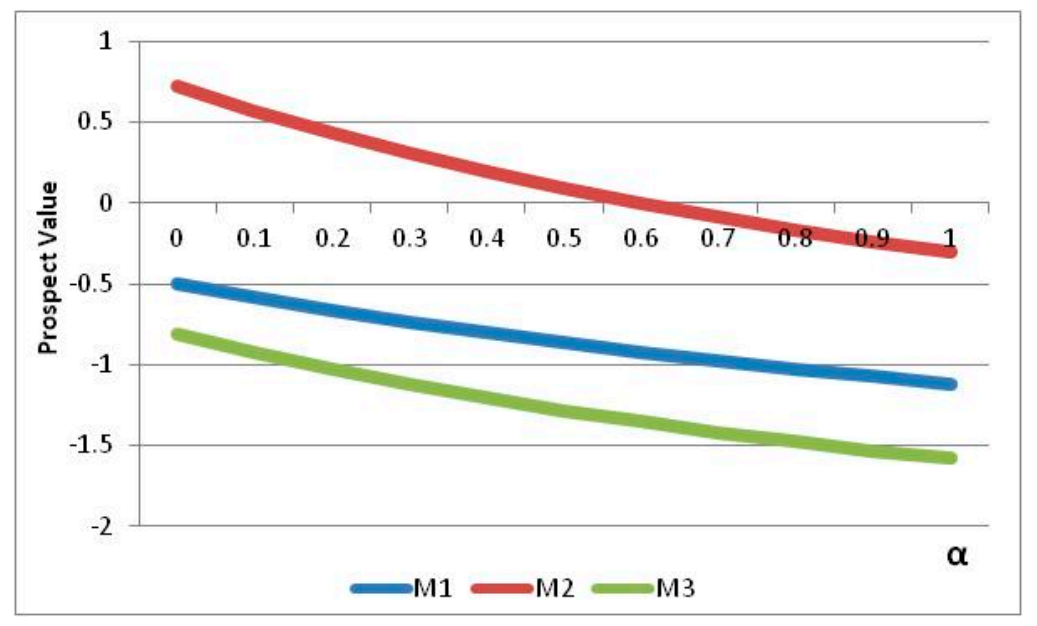

Figure 4. The integrated prospect values of three micro-grid planning programs with different $\alpha$ values.

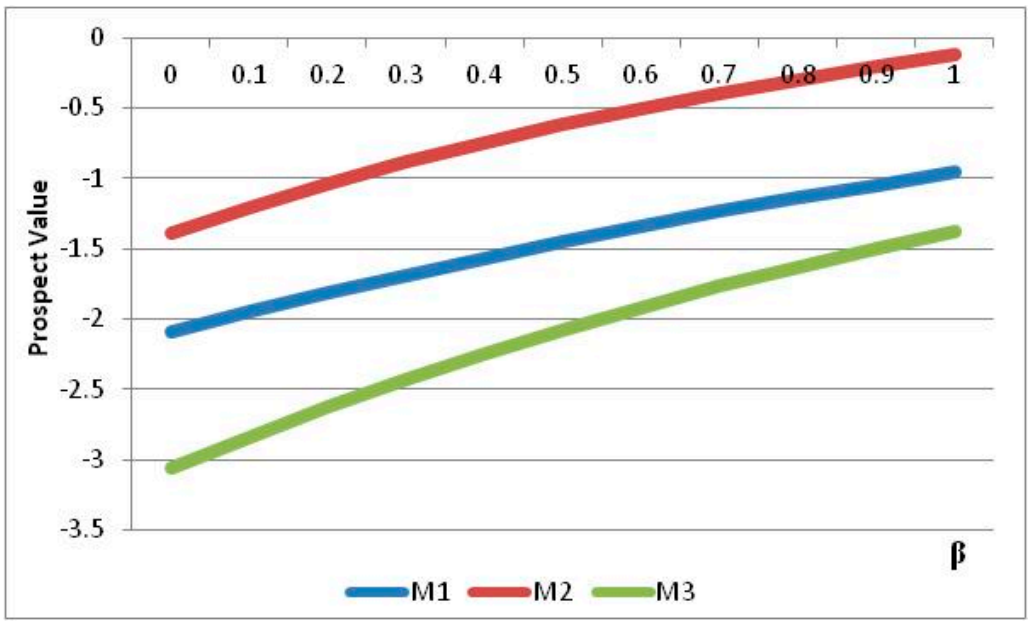

Figure 5. The integrated prospect values of three micro-grid planning programs with different $\beta$ values.

\section{Conclusions}

With the continuously increasing emphasis on the planning and operation of the micro-grid demonstration projects by China's central government, the evaluation on micro-grid planning programs, as a significant part of the micro-grid planning, can comprehensively evaluate the performances of all micro-grid planning program alternatives and select the optimal micro-grid planning program, which can provide convincing reference for the decision making of the micro-grid planning. This paper proposes a novel MCDM model combining the BWM, the entropy weighting approach, and GCPT for optimum planning program selection of micro-grid construction. The significant conclusions are summarized as below.

(1) To comprehensively depict the features of the micro-grid systems, the assessment index system was built from the perspectives of economy, electricity supply reliability and environmental protection, which totally contains 18 sub-criteria.

(2) The weights of sub-criteria were calculated via integrating the subjective weights judged by the BWM and the objective weights computed by the entropy weighting approach. The importance of the distribution network infrastructure investment delayed income, NPV of micro-grid construction, annual electricity generation amount to network, micro-grid total investment, the electric power quality qualification rate, and the proportion of renewable energy installed were highlighted. 
(3) The CPT combined with grey theory was employed to select the optimal micro-grid planning program, and the program with $100 \mathrm{kWp}$ photovoltaic power generation unit, $200 \mathrm{~kW}$ wind power generation unit, and $600 \mathrm{kWh} \mathrm{NaS}$ battery energy storage system is selected as the optimal micro-grid planning program.

(4) Sensitivity analysis related to parameters values change under different risk preferences was conducted to verify the robustness of the evaluated results. The results indicate that no matter what kinds of risk preferences the DM and investors may have, taking the economic criterion, the electricity supply reliability perspective and the environmental protection aspect into consideration, the selected optimal micro-grid planning program will not be influenced.

Although it is justified that the established novel MCDM model is applicable and feasible for evaluating different micro-grid planning programs and selecting the optimal program, considering about the complexity of the micro-grid planning program evaluation, with the development of the micro-grid planning and construction, the evaluation index system will be adjusted and improved in the future. Additionally, the proposed novel MCDM method in this paper can also be applied to other issues, such as comprehensive energy system planning evaluation.

Author Contributions: H.Z. (Huiru Zhao) and S.G. proposed the researching framework. H.Z. (Haoran Zhao) conducted the empirical analysis and wrote the manuscript. S.G. provided several useful recommendations on the manuscript revision.

Funding: This research was funded by the Major State Research and Development Program of China grant number 2016YFB0900500.

Acknowledgments: This paper is supported by the Major State Research and Development Program of China under Grant No. 2016YFB0900500.

Conflicts of Interest: The authors declare no conflict of interest.

\section{References}

1. Kröger, W. Critical infrastructures at risk: A need for a new conceptual approach and extended analytical tools. Reliab. Eng. Syst. Saf. 2008, 93, 1781-1787. [CrossRef]

2. Zhao, H.; Li, N. Evaluating the performance of thermal power enterprises using sustainability balanced scorecard, fuzzy Delphic and hybrid multi-criteria decision making approaches for sustainability. J. Clean. Prod. 2015, 108, 569-582. [CrossRef]

3. Midilli, A.; Ibrahim, D.; Murat, A. Green energy strategies for sustainable development. Energy Policy 2006, 34, 3623-3633. [CrossRef]

4. Borchers, A.M.; Duke, J.M.; Parsons, G.R. Does willingness to pay for green energy differ by source? Energy Policy 2007, 35, 3327-3334. [CrossRef]

5. Theo, W.L.; Lim, J.S.; Ho, W.S.; Hashim, H.; Lee, C.T. Review of distributed generation (DG) system planning and optimisation techniques: Comparison of numerical and mathematical modelling methods. Renew. Sustain. Energy Rev. 2017, 67, 531-573. [CrossRef]

6. Cortes, C.A.; Contreras, S.F.; Shahidehpour, M. Microgrid Topology Planning for Enhancing the Reliability of Active Distribution Networks. IEEE Trans. Smart Grid 2017, 1-9. [CrossRef]

7. Zeng, Z.; Zhao, R.; Yang, H.; Tang, S. Policies and demonstrations of micro-grids in China: A review. Renew. Sustain. Energy Rev. 2014, 29, 701-718. [CrossRef]

8. Wang, C.; Li, P. Development and challenges of distributed generation, the micro-grid and smart distribution system. Autom. Electr. Power Syst. 2010, 34, 10-14.

9. Wu, M.; Zhao, T.; Zhao, F.; Zhang, Y.; Kou, L.; Zhou, X. Evaluation Index System of Microgrid Operation Effect and Corresponding Evaluation Method. Power Syst. Technol. 2018, 42, 690-697.

10. Pilot Measures for Promoting the Construction of the Grid Connected Micro-grid. Available online: http: / / www.ndrc.gov.cn/gzdt/201707/W020170724352631872957.pdf (accessed on 20 April 2018).

11. Notice on the List of New Energy Micro-grid Demonstration Projects. Available online: http://www. sdfgw.gov.cn/module/download/downfile.jsp?classid=0\&filename=1705271126190989191.pdf (accessed on 20 April 2018). 
12. Bahmani-Firouzi, B.; Azizipanah-Abarghooee, R. Optimal sizing of battery energy storage for micro-grid operation management using a new improved bat algorithm. Int. J. Electr. Power Energy Syst. 2014, 56, $42-54$. [CrossRef]

13. Ekren, O.; Ekren, B.Y. Size optimization of a PV/wind hybrid energy conversion system with battery storage using simulated annealing. Appl. Energy 2010, 87, 592-598. [CrossRef]

14. Borhanazad, H.; Mekhilef, S.; Ganapathy, V.G.; Modiri-Delshad, M.; Mirtaheri, A. Optimization of micro-grid system using MOPSO. Renew. Energy 2014, 71, 295-306. [CrossRef]

15. Zheng, L.W.; Liu, S.R.; Zhou, W.J.; Li, J.L.; Wu, S.Y. Capacity configuration and optimization of grid-connected renewable energy power generation system. Power Syst. Prot. Control 2014, 42, 31-37.

16. Gamarra, C.; Guerrero, J.M. Computational optimization techniques applied to microgrids planning: A review. Renew. Sustain. Energy Rev. 2015, 48, 413-424. [CrossRef]

17. Amrollahi, M.H.; Bathaee, S.M.T. Techno-economic optimization of hybrid photovoltaic/wind generation together with energy storage system in a stand-alone micro-grid subjected to demand response. Appl. Energy 2017, 202, 66-77. [CrossRef]

18. Jiao, Y.; Wu, J.; Tan, Q.; Tan, Z.; Wang, J. An optimization model and modified harmony search algorithm for microgrid planning with ESS. Discret. Dyn. Nat. Soc. 2017, 2017, 8425458. [CrossRef]

19. Izadbakhsh, M.; Gandomkar, M.; Rezvani, A.; Ahmadi, A. Short-term resource scheduling of a renewable energy based micro grid. Renew. Energy 2015, 75, 598-606. [CrossRef]

20. Buayai, K.; Ongsakul, W.; Mithulananthan, N. Multi-objective micro-grid planning by NSGA-II in primary distribution system. Int. Trans. Electr. Energy Syst. 2012, 22, 170-187. [CrossRef]

21. Shu, J.; Zhang, X.Y.; Shen, Y.L.; Wu, C.H. The algorithm and application in power sources planning and designing for micro-grid based on distributed renewable energy. Control Theory Appl. 2010, 27, 675-680.

22. Han, X.; Zhang, H.; Yu, X.; Wang, L. Economic evaluation of grid-connected micro-grid system with photovoltaic and energy storage under different investment and financing models. Appl. Energy 2016, 184, 103-118. [CrossRef]

23. Nieto, A.; Vita, V.; Maris, T.I. Power quality improvement in power grids with the integration of energy storage systems. Int. J. Eng. Res. Technol. 2016, 5, 438-443.

24. Vita, V. Development of a decision-making algorithm for the optimum size and placement of distributed generation units in distribution networks. Energies 2017, 10, 1433. [CrossRef]

25. Chen, Q.; Yu, C.; Zhang, J.; Liu, W.; Wang, J. Application of analytic hierarchy process in comprehensive evaluation of island microgird. J. Power Syst. Autom. 2013, 25, 133-137.

26. Vasiljevska, J.; Lopes, J.P.; Matos, M.A. Evaluating the impacts of the multi-microgrid concept using multicriteria decision aid. Electr. Power Syst. Res. 2012, 91, 44-51. [CrossRef]

27. Miao, Y.; Cheng, H.; Gong, X.; Wang, L.; Yao, L.; Masoud, B. Evaluation of a distribution network connection mode considering micro-grid. Proc. Chin. Soc. Electr. Eng. 2012, 32, 17-23.

28. Yang, Q.; Ma, S.; Tang, X.; Li, X. Evaluation index system construction and application of microgrid planning. Autom. Electr. Power Syst. 2012, 36, 13-17.

29. Liu, Y.; Fan, Z.P.; Zhang, Y. Risk decision analysis in emergency response: A method based on cumulative prospect theory. Comput. Oper. Res. 2014, 42, 75-82. [CrossRef]

30. Wang, L.; Wang, Y.M.; Martínez, L. A group decision method based on prospect theory for emergency situations. Inf. Sci. 2017, 418, 119-135. [CrossRef]

31. Wu, Y.; Xu, C.; Zhang, T. Evaluation of renewable power sources using a fuzzy MCDM based on cumulative prospect theory: A case in China. Energy 2018, 147, 1227-1239. [CrossRef]

32. Wilton, E.; Delarue, E.; D'haeseleer, W.; van Sark, W. Reconsidering the capacity credit of wind power: Application of cumulative prospect theory. Renew. Energy 2014, 68, 752-760. [CrossRef]

33. Ren, Y.L.; Zhou, Y.L.; Shi, L.F. Decision-making approach in charging mode for electric vehicle based on cumulative prospect theory. In Proceedings of the 5th China International Conference on Electricity Distribution (CICED), Shanghai, China, 10-14 September 2012; pp. 1-4.

34. Klein, M.; Deissenroth, M. When do households invest in solar photovoltaics? An application of prospect theory. Energy Policy 2017, 109, 270-278. [CrossRef]

35. Liu, J.; Xu, F.; Lin, S. Site selection of photovoltaic power plants in a value chain based on grey cumulative prospect theory for sustainability: A case study in Northwest China. J. Clean. Prod. 2017, 148, 386-397. [CrossRef] 
36. Li, C.B.; Yuan, J.H.; Gao, P. Risk decision-making based on Mahalanobis-Taguchi system and grey cumulative prospect theory for enterprise information investment. Intell. Decis. Technol. 2016, 10, 49-58. [CrossRef]

37. Rezaei, J. Best-worst multi-criteria decision-making method. Omega 2015, 53, 49-57. [CrossRef]

38. Rezaei, J. Best-worst multi-criteria decision-making method: Some properties and a linear model. Omega 2016, 64, 126-130. [CrossRef]

39. Rezaei, J.; Nispeling, T.; Sarkis, J.; Tavasszy, L. A supplier selection life cycle approach integrating traditional and environmental criteria using the best worst method. J. Clean. Prod. 2016, 135, 577-588. [CrossRef]

40. Hafezalkotob, A.; Hafezalkotob, A. A novel approach for combination of individual and group decisions based on fuzzy best-worst method. Appl. Soft Comput. 2017, 59, 316-325. [CrossRef]

41. Ren, J.; Liang, H.; Chan, F.T.S. Urban sewage sludge, sustainability, and transition for Eco-City: Multi-criteria sustainability assessment of technologies based on best-worst method. Technol. Forecast. Soc. Chang. 2017, 116, 29-39. [CrossRef]

42. Guo, S.; Zhao, H. Fuzzy best-worst multi-criteria decision-making method and its applications. Knowl. Based Syst. 2017, 121, 23-31. [CrossRef]

43. Ahmadi, H.B.; Kusi-Sarpong, S.; Rezaei, J. Assessing the social sustainability of supply chains using Best Worst Method. Resour. Conserv. Recycl. 2017, 126, 99-106. [CrossRef]

44. Chitsaz, N.; Azarnivand, A. Water scarcity management in arid regions based on an extended multiple criteria technique. Water Resour. Manag. 2017, 31, 233-250. [CrossRef]

45. Gupta, H. Evaluating service quality of airline industry using hybrid best worst method and VIKOR. J. Air Transp. Manag. 2018, 68, 35-47. [CrossRef]

46. Salimi, N.; Rezaei, J. Evaluating firms' R\&D performance using best worst method. Eval. Progr. Plan. 2018, 66, 147-155.

47. Zhao, H.; Guo, S.; Zhao, H. Comprehensive benefit evaluation of eco-industrial parks by employing the best-worst method based on circular economy and sustainability. Environ. Dev. Sustain. 2017, 20, 1229-1253. [CrossRef]

48. Shemshadi, A.; Shirazi, H.; Toreihi, M.; Tarokh, M.J. A fuzzy VIKOR method for supplier selection based on entropy measure for objective weighting. Expert Syst. Appl. 2011, 38, 12160-12167. [CrossRef]

49. Zhao, H.; Zhao, H.; Guo, S. Evaluating the comprehensive benefit of eco-industrial parks by employing multi-criteria decision making approach for circular economy. J. Clean. Prod. 2017, 142, 2262-2276. [CrossRef]

50. Tversky, A.; Kahneman, D. Advances in prospect theory: Cumulative representation of uncertainty. J. Risk Uncertain. 1992, 5, 297-323. [CrossRef]

51. Tversky, A.; Kahneman, D. Advances in Prospect Theory: Cumulative Representation of Uncertainty. In Readings in Formal Epistemology; Springer: Berlin, Germany, 2016; pp. 493-519.

52. Song, J.; Dang, Y.-G.; Li, X.-M.; Wang, Z.-X. Grey risk group decision based on the majorant operator of rewarding good and punishing bad. J. Grey Syst. 2009, 21, 377-386.

53. Zhou, L. Research on the Micro-grid Planning Comprehensive Evaluation. Master's Thesis, Yanshan University, Qinhuangdao, China, 2013.

54. Ibrahim, H.; Ilinca, A.; Perron, J. Energy storage systems-Characteristics and comparisons. Renew. Sustain. Energy Rev. 2008, 12, 1221-1250. [CrossRef]

55. Sen, R.; Bhattacharyya, S.C. Off-grid electricity generation with renewable energy technologies in India: An application of HOMER. Renew. Energy 2014, 62, 388-398. [CrossRef]

(C) 2018 by the authors. Licensee MDPI, Basel, Switzerland. This article is an open access article distributed under the terms and conditions of the Creative Commons Attribution (CC BY) license (http://creativecommons.org/licenses/by/4.0/). 